\title{
Barriers and Opportunities of E-Learning Implementation in Iraq: A Case of Public Universities
}

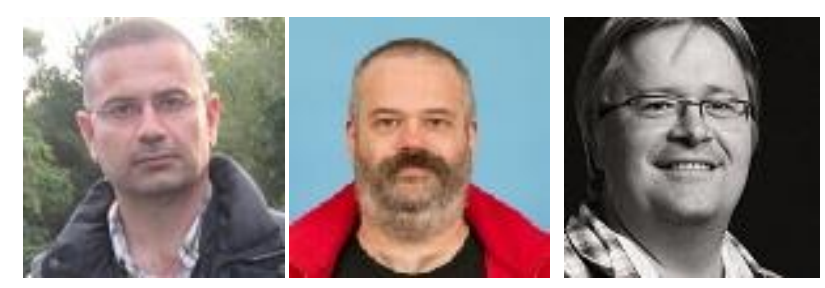

Ahmed Al-Azawei 1,2, Patrick Parslow ${ }^{1}$, and Karsten Lundqvist ${ }^{1}$ 1 University of Reading, Reading, United Kingdom, 2University of Babylon, Babel, Iraq

\begin{abstract}
Although the implementation of e-learning initiatives has reached advanced stages in developed countries, it is still in its infancy in many developing nations and the Middle East in particular. Recently, few public universities in Iraq have initiated limited attempts to use e-learning alongside traditional classrooms. However, different obstacles are preventing successful adoption of this technology. The present research aimed to highlight challenges that hinder effective implementation of e-learning in Iraq and recommend possible solutions to tackle them. A total of 108 respondents voluntarily participated in this research. They consisted of academic staff $(\mathrm{N}=74)$, professors in charge of e-learning $(\mathrm{N}=3)$, and undergraduate students $(\mathrm{N}=31)$. Three methods were used to collect data: a survey instrument, semi-structured interviews, and focus groups. Data was then analyzed and reported quantitatively and qualitatively. This provided in-depth understanding to the current status of e-learning in public Iraqi universities and highlighted major hindrances of its successful application. Based on this analysis, the study proffered many recommendations that should be considered in order to fully benefit from e-learning technologies.
\end{abstract}

Keywords: Information Communication Technologies (ICTs), e-learning, developing countries, challenges of e-learning application

\section{Introduction}

The rapid growth of Information and Communication Technologies (ICTs) in the last decades has reshaped the forms of teaching and learning in Higher Education (Pulkkinen, 2007; Sife, Lwoga, \& Sanga, 2007). Although many forms of ICT innovations have been used for educational purposes comprising "computers, the Internet, broadcasting technologies (radio and television), and telephony" (Khan, Hasan, \& Clement, 2012; p. 67), Learning Management Systems (LMSs) have attracted a 
significant consideration in Higher Education. Alias \& Zainuddin (2005; p. 28) defined LMSs as "a software application or web-based technology used to plan, implement, and assess a specific learning process.”. Other synonyms for LMSs include Course Management Systems (CMSs), Virtual Learning Environments (VLEs), and Knowledge Management Systems (KMSs) (Alias \& Zainuddin, 2005; Graf, 2007). Both teachers and learners can benefit from this technology. The former can upload and present learning content, track learner activities, assess learner knowledge, and keep students up to date about a course. The latter can access learning content anytime and from anyplace, interact with their peers or instructors, ask questions, and upload their work. In fact, one can safely assert that elearning will soon constitute a dominant tool in present educational systems. However, as with other new terminologies of learning in the digital era, e-learning does not have an acceptable definition among all researchers. Sun, Tsai, Finger, Chen, \& Yeh (2008; p. 1184) defined e-learning as "basically a web-based system that makes information or knowledge available to users or learners and disregards time restrictions or geographic proximity." Procter (2003), on the other hand, adopted that e-learning refers to "the delivery of learning with the assistance of interactive, electronic technology, whether offline or online". For the purposes of this study, however, e-learning was restricted to the use of the internet as a medium of education delivery.

While developed countries have made significant strides toward integrating e-learning platforms in Higher Education, developing ones have not yet effectively adopted such technologies (Ali \& Magalhaes, 2008; Al-Senaidi, Lin, \& Poirot, 2009; Gulati, 2008; Sife et al., 2007; Ssekakubo, Suleman, \& Marsden, 2011; Tarus, Gichoya, \& Muumbo, 2015). Specifically, there is an obvious delay in e-learning adoption within most educational systems in the Middle East region (Matar, Hunaiti, Halling, \& Matar, 2010; Mirza \& Al-Abdulkareem; 2011). Studies recognize serious challenges that inhibit the effective integration of e-learning in Higher Education (Ali \& Magalhaes, 2008; Al Musawi \& Abdelraheem, 2004). As such, while considering the benefits of e-learning as a tool to enhance the delivery of education, barriers to adopting this technology should also be considered; especially in countries such as Iraq, since respective research has been notably scarce.

Unsurprisingly, Iraq is the last country in the Middle East to implement e-learning innovations (Matar et al., 2010). According to Mirza \& Al-Abdulkareem (2011), only 1\% of the Iraqi population had internet access until the end of 2009. Therefore, Iraq remains behind the great revolution of ICTs in Higher Education. Recently, the Iraqi Ministry of Higher Education and Scientific Research (MHESRI) took serious steps to rehabilitate this sector, albeit in pertinence to the traditional learning approaches; strategies for e-learning adoption have been limited. Accordingly, further investigation into e-learning use in Iraq is required in order to fill in this gap of research, and extend the body of existing literature by highlighting major barriers in the endorsement of such technologies for teaching and learning in the Middle East.

\section{Objectives}

In this research, in addition to a review of core e-learning barriers in the Middle East, the main focus is on Iraqi academic staff and student perspectives of what are the key challenges to the use of elearning in Higher Education. A presentation of results of this analysis is followed by recommendations regarding possible practical solutions to aid toward e-learning implementation. According to the best of the authors' knowledge, this area of research is unexplored in Iraq because elearning is a new experience in all public Iraqi universities. Hence, the present paper seeks to: 
- identify the current status of e-learning application in public Iraqi universities;

- highlight challenges that hinder the effective integration of e-learning; and

- recommend possible practical solutions that can be followed to address such barriers.

\section{Literature Review}

Recently, a plethora of studies focusing on e-learning integration in developing countries has emerged. Researchers have conducted qualitative and quantitative analyses to pinpoint issues that can prevent its successful implementation. Previously determined issues are reviewed as follows.

\section{E-Learning Advantages}

The application of e-learning has significant impacts on Higher Education. In this era, learners can flexibly choose the most appropriate learning mode in accordance with their preferences or commitments, or both. Previous studies demonstrate that effective e-learning implementation is a means to solve authentic issues of learning and achievement (Govindasamy, 2002). This section reports main advantages of e-learning as summarized from literature (Al-Din \& AlRadhi, 2008; Derouin, Fritzsche, \& Salas, 2005; Sife et al., 2007; Zhang, Zhao, Zhou, \& Nunamaker, 2004).

- Information accessibility: students can easily access learning content anytime and anywhere. Another possible advantage of information accessibility is that learning technologies can serve learners' special needs.

- Adaptivity and adaptability: it could be very difficult to accommodate teaching approaches, content presentation, and learning pathways to an individual learner in a traditional learning mode, but this is quite possible in e-learning.

- Efficient interaction: e-learning can provide additional and alternative interaction opportunities out of campus and normal work hours.

- Cooperation and collaboration: both can be improved using available communication tools in LMSs such as forums, wiki, and chat as well as assigning learners into different groups to work together.

- Teaching and learning in a synchronous or an asynchronous mode: learners and teachers can choose the most appropriate method to deliver and receive learning content.

- Reducing cost: learners can avoid tuition fees following e-learning courses. Additionally, elearning can eliminate traveling expenditure, and save time and effort.

- Promoting teaching quality: e-learning functionalities can be exploited to integrate pedagogical theories and make lessons more interactive.

- Ease of managing and tracking learner activities: LMSs provide rich log files that track learner activities within the system. 
- Self-paced learning and learner-centred environment: face-to-face (F2F) approach relies heavily on teachers. This does not work effectively for all students considering the inequality of age-groups and background knowledge.

\section{E-Learning Application and Challenges in Developing Countries}

Developing nations are categorized as such because their rank in the United Nations Development Program (UNDP) Human Development Index is low. Prior studies attempted to identify challenges that hinder effective implementation of e-learning in developing countries. Each study considered a particular case to understand this phenomenon. On the other side, developing countries have apparent differences in their cultures, level of education, and economic state. Hence, further analysis is required, especially in countries where little or no research has been conducted.

Gulati (2008) reviewed the integration of Technology Enhanced Learning (TEL) in different developing nations. The study showed that there is potential for e-learning initiatives in order to develop the education sector in these countries. However, poverty and lack of ICT infrastructure are the main issues that have been revealed. Moreover, Zamani and Esfijani (2016) classified obstacles that developing countries face in e-learning use into three groups. The first one is called "personal challenges." This group includes factors that associated with internal personal features, characteristics, and behavioural habits. The second group is "attitudinal inhibitors." It encompasses internal variables that are more relevant to attitudes and perspectives of users regarding e-learning features. Finally, "contextual inhibitors" group is relevant to external variables that comprise the lack of ICTs skills and organizational support in the use of e-learning technologies. Table 1 chronologically summarizes major challenges that hinder effective adoption of e-learning in developing nations.

Table 1

Challenges Hindering E-Learning Uptake in Developing Countries

\begin{tabular}{lcl}
\hline Study & Country & Challenges \\
\hline Sife et al. (2007) & Tanzania & $\begin{array}{l}\text { Systematic approach, awareness, and attitudes of } \\
\text { stakeholders, administrative support, technical support, } \\
\text { staff development, transforming Higher Education, lack } \\
\text { of funds, and ownership. }\end{array}$ \\
\hline Andersson (2008) & Sri Lanka & $\begin{array}{l}\text { Student support, flexibility, activities of teaching and } \\
\text { learning, internet access, student academic confidence, } \\
\text { localization of content to fit a particular culture, and } \\
\text { attitudes toward e-learning. }\end{array}$ \\
\hline Ssekakubo et al. (2011) & Africa & $\begin{array}{l}\text { Internet accessibility, knowledge gap of stakeholders, } \\
\text { ICT illiteracy, undefined strategies, inadequate selection } \\
\text { of LMSs, and inefficient user support. }\end{array}$ \\
\hline $\begin{array}{l}\text { Khan, Hasan, \& Clement } \\
\text { (2012) }\end{array}$ & Bangladesh & $\begin{array}{l}\text { ICT infrastructure, insufficient fund, unclear plan, } \\
\text { political factors, cultural factors, corruption, teachers } \\
\text { attitudes, ICT skills, and lack of time. }\end{array}$ \\
\hline Elzawi \& Wade (2012) & Libya & $\begin{array}{l}\text { Internet access, low internet connectivity, lack of } \\
\text { encouragement, English proficiency, training programs, } \\
\text { cost of internet, technical skills, disinterest, and social } \\
\text { restrictions. }\end{array}$ \\
\hline Tarus et al. (2015) & Kenya & $\begin{array}{l}\text { ICTs and e-learning infrastructure, financial support, low } \\
\text { internet bandwidth, inadequate policies, technical skills, } \\
\text { teacher attitude, and time cost to prepare e-resources. }\end{array}$ \\
\hline
\end{tabular}




\section{Status of E-Learning in the Middle East}

The Arab Middle East region is comprised by Bahrain, Iraq, Jordan, Kuwait, Lebanon, Oman, Palestine, Qatar, Saudi Arabia, Syria, the United Arab Emirates (UAE), and Yemen. In these countries, many universities have taken great steps in adopting e-learning by the early of the last decade. A brief history on the use of e-learning in different Middle East nations is summarized below:

Internet Usage. In today's education, internet represents the most dominant medium for the provision of e-learning. As exhibited in Table 2, it is obvious that the overall internet penetration in the Middle East is at an acceptable level (52.2\%) in comparison to the rest of the world. Generally, from 2009 to 2015, a significant growth (23.9\%) of internet usage was observed in the Middle East (Table 3).

Table 2

Internet Users in the Middle East and the World until November 30, 2015 (Internet World Stats, 2015)

\begin{tabular}{llllll}
\hline $\begin{array}{l}\text { MIDDLE } \\
\text { EAST }\end{array}$ & $\begin{array}{l}\text { Population } \\
\text { (2015 Est.) }\end{array}$ & $\begin{array}{l}\text { Pop. \% of } \\
\text { the World }\end{array}$ & Internet Users & $\begin{array}{l}\text { Population } \\
\text { (Penetration) } \%\end{array}$ & $\begin{array}{l}\text { Internet } \\
\text { \% users }\end{array}$ \\
\hline $\begin{array}{l}\text { Total Middle } \\
\text { East }\end{array}$ & $\mathbf{2 3 6 , 1 3 7 , 2 3 5}$ & $\mathbf{3 . 3} \%$ & $\mathbf{1 2 3 , 1 7 2 , 1 3 2}$ & $\mathbf{5 2 . 2} \%$ & $\mathbf{3 . 7} \%$ \\
\hline $\begin{array}{l}\text { Rest of the } \\
\text { World }\end{array}$ & $7,023,765,008$ & $96.7 \%$ & $3,243,087,924$ & $46.2 \%$ & $96.3 \%$ \\
\hline World Total & $7,259,902,243$ & $100.0 \%$ & $3,366,260,056$ & $46.4 \%$ & $100.0 \%$ \\
\hline
\end{tabular}

Table 3 illustrates that the highest level of the internet penetration has been achieved by Bahrain (96.4\%) with growth rate (GR) of 41.4 from 2010 to 2015. This is followed by United Arab Emirates (UAE) with 93.2\% (GR=32.3\%), Qatar around 92\% (GR=39.6\%), Jordan with 86.1\% (GR=62.2\%), and Saudi Arabia around 66\% (GR=39.1\%). Iraq shows a substantial improvement in internet usage, growing from $1 \%$ (2009), $9 \%$ (2014), to $33 \%$ by the end of 2015. This could be an indicator about the improvement of ICT infrastructure. On the other hand, it is still under development in comparison to other nations in the region.

Table 3

A Comparison of Internet Usage in Middle East Countries Until November 30, 2015 (Internet World Stats, 2015)

\begin{tabular}{|c|c|c|c|c|c|c|c|}
\hline $\begin{array}{l}\text { MIDDLE } \\
\text { EAST }\end{array}$ & $\begin{array}{l}\text { Population } \\
\text { (2015 Est.) }\end{array}$ & $\begin{array}{l}\text { Users, in } \\
\text { Dec/2000 }\end{array}$ & $\begin{array}{l}\text { Internet } \\
\text { Usage/2014 }\end{array}$ & $\begin{array}{l}\text { Internet } \\
\text { Usage/2014 }\end{array}$ & $\begin{array}{l}\text { Population } \\
\text { (Penetration) } \\
2009 \%\end{array}$ & $\begin{array}{l}\text { Population } \\
\text { (Penetration) } \\
2014 \%\end{array}$ & $\begin{array}{l}\text { Population } \\
\text { (Penetration) } \\
2015 \%\end{array}$ \\
\hline Bahrain & $1,346,613$ & 40,000 & $1,297,500$ & $1,297,500$ & 55.3 & $96.4 \%$ & $96.4 \%$ \\
\hline Iran & $81,824,270$ & 250,000 & $46,800,000$ & $46,800,000$ & 48.5 & $57.2 \%$ & $57.2 \%$ \\
\hline Iraq & $33,309,836$ & 12,500 & 2,997,884 & $11,000,000$ & 1.0 & $9.0 \%$ & $33.0 \%$ \\
\hline Israel & $7,935,149$ & $1,270,000$ & $5,928,772$ & $5,928,772$ & 72.8 & $74.7 \%$ & $74.7 \%$ \\
\hline Jordan & $6,623,279$ & 127,300 & $5,700,000$ & $5,700,000$ & 23.9 & $86.1 \%$ & $86.1 \%$ \\
\hline Kuwait & $3,996,899$ & 150,000 & $3,022,010$ & $3,145,559$ & 37.1 & $75.6 \%$ & $78.7 \%$ \\
\hline Lebanon & $4,151,234$ & 300,000 & $3,336,517$ & $3,336,517$ & 23.5 & $80.4 \%$ & $80.4 \%$ \\
\hline Oman & $3,286,936$ & 90,000 & $2,584,316$ & $2,584,316$ & 13.6 & $78.6 \%$ & $78.6 \%$ \\
\hline $\begin{array}{l}\text { Palestine } \\
\text { (West } \\
\text { Bk.) }\end{array}$ & $2,785,366$ & 35,000 & $1,687,739$ & $1,800,000$ & 14.4 & $60.6 \%$ & $64.6 \%$ \\
\hline
\end{tabular}




\begin{tabular}{|c|c|c|c|c|c|c|c|}
\hline Qatar & $2,194,817$ & 30,000 & $2,016,400$ & $2,016,400$ & 52.3 & $91.9 \%$ & $91.9 \%$ \\
\hline $\begin{array}{l}\text { Saudi } \\
\text { Arabia }\end{array}$ & $27,752,316$ & 200,000 & $18,300,000$ & $18,300,000$ & 26.8 & $65.9 \%$ & $65.9 \%$ \\
\hline Syria & $22,878,524$ & 30,000 & $5,920,553$ & $6,426,577$ & 16.4 & $25.9 \%$ & $28.1 \%$ \\
\hline UAE & $9,445,624$ & 735,000 & $8,807,226$ & $8,807,226$ & 60.9 & $93.2 \%$ & $93.2 \%$ \\
\hline Yemen & $26,737,317$ & 15,000 & $5,210,593$ & $6,029,265$ & 1.6 & $19.5 \%$ & $22.6 \%$ \\
\hline $\begin{array}{l}\text { Gaza } \\
\text { Strip }\end{array}$ & $1,869,055$ & $\mathrm{n} / \mathrm{a}$ & $\mathrm{n} / \mathrm{a}$ & $\mathrm{n} / \mathrm{a}$ & $\mathrm{n} / \mathrm{a}$ & $\mathrm{n} / \mathrm{a}$ & $\mathrm{n} / \mathrm{a}$ \\
\hline $\begin{array}{l}\text { TOTAL } \\
\text { Middle } \\
\text { East }\end{array}$ & $236,137,235$ & $3,284,800$ & $113,609,510$ & $123,172,132$ & 28.3 & $48.1 \%$ & $52.2 \%$ \\
\hline
\end{tabular}

E-Learning Application and Challenges in the Middle East. The evaluation of elearning integration in Arab Middle East nations revealed that the leading position in the use of elearning was achieved by UAE, Jordan, and Saudi Arabia (Matar et al., 2010; Mirza \& AlAbdulkareem, 2011). The UAE has been highlighted as "the most advanced e-learning country in the Arab world" (Taha, 2007; p. 353). In 1997, the Centre of Excellence for Applied Research and Training (CERT) was founded as the largest education provider in the Middle East, with the aim to provide education, training, and applied technology (Watt,2012). Likewise, In Oman, Al Musawi \& Abdelraheem (2004) pointed out that WebCT was adopted at Sultan Qaboos University in 2001. Initially, it offered only eight online courses for 981 learners. At the end of 2002, the university offered 40 online courses with a total of 3,001 users enrolled. Although Jordan has been considered one of the pioneer nations of e-learning uptake in the Middle East, the first distance e-learning forum was held in 2003 (Al-Shboul \& Alsmadi, 2010). Following other Arab Gulf countries, Saudi Arabia also moved on to adopt e-learning. The National Centre for E-learning and Distance Learning was initialized in 2005, with the objective of integrating e-learning in the educational system (Yamani, 2014). Thus, the utility of e-learning in most Middle East nations has been realized since the beginning of the last decade in order to reinforce learning; yet its successful implementation is moving very slowly.

Mirza and Al-Abdulkareem (2011) reported three categories of e-learning uptake in the Middle East: virtual e-learning, hybrid e-learning, and blended e-learning models. Examples of the first established category are Syrian Virtual University in 2002, Hamdan bin Mohammed e-University in Dubai in 2002, the Mediterranean Virtual University in Jordan in 2004, and Knowledge International University in Saudi Arabia in 2007. The second category comprises, but is not limited to, Arab Open University, which was inaugurated in Kuwait, Jordan, and Lebanon in 2002, but later it expanded to include other branches in Saudi Arabia, Oman, and Egypt. The third category represents the most dominant approach in Higher Education. Only WebCT accounted 45 customers in the Middle East in 2004 including non-academic organizations. In Yemen, Microsoft Learning Gateway was successfully deployed to serve all students in the University of Saan'a in 2004. Hence, it was concluded that comparing e-learning application in this region with that in Western countries can clearly present that it remains at an initial level (Matar et al., 2010). Table 4 summarizes the concluded barriers of elearning adoption in some of the Arab Middle East nations.

Table 4

Challenges Hindering E-Learning Uptake in Middle East Countries

\begin{tabular}{lcl}
\hline Study & Country & Challenges \\
\hline Abdelraheem (2006) & Oman & $\begin{array}{l}\text { E-learning infrastructure, culture of Arabic people, } \\
\text { strategies of e-learning adoption, issues of copyright, } \\
\text { individual features of both students and instructors, and }\end{array}$ \\
\hline
\end{tabular}




\begin{tabular}{|c|c|c|}
\hline & & the web content was very limited for Arab population. \\
\hline Ali \& Magalhaes (2008) & Kuwait & $\begin{array}{l}\text { Lack of institutional support, language obstacles, IT } \\
\text { issues, and workload and lack of time. }\end{array}$ \\
\hline Al-Senaidi et al. (2009) & Oman & $\begin{array}{l}\text { Lack of equipment, lack of confidence, lack of } \\
\text { institutional support, doubt in ICT benefits, and lack of } \\
\text { time. }\end{array}$ \\
\hline Matar et al. (2010) & Middle East & ICT infrastructure and lack of electronic resources. \\
\hline $\begin{array}{l}\text { Mirza \& Al-Abdulkareem } \\
\text { (2011) }\end{array}$ & Saudi Arabia & $\begin{array}{l}\text { Rate of internet penetration, bandwidth and cost of the } \\
\text { internet, and low esteem of public for web-based } \\
\text { learning. }\end{array}$ \\
\hline Al-Shboul (2013) & Jordan & $\begin{array}{l}\text { Lack of institutional encouragement and support as well } \\
\text { as improper training. }\end{array}$ \\
\hline
\end{tabular}

\section{Current Status of ICTs in Higher Education in Iraq}

Context of Higher Education. Iraq is located in the east of the Arabian Peninsula. Its ancient civilizations, such as the Assyrians, Babylonians, and Chaldeans, have been accounted to have been the first of their kind in the world. With such recorded history backdated more than 8000 years, Iraq was one of the leaders in the Arab region. Saheb (2005) stated that primitive forms of schools and universities had begun in Egypt and Babylon. Moreover, approximately ten centuries ago, Baghdad represented the hub of different scientific sectors. In the modern era, the education system in Iraq has been considered the best in the region (Kaghed \& Dezaye, 2009). A free education at all levels, including Higher Education, is provided for all Iraqi citizens.

From 1975 to 1985, billions were spent to promote the education domain in Iraq. As such, this period was known as the golden era of education. The government established a number of projects to support learning technologies such as computer laboratories, computer centres, and closed-circuit TV (Elameer \& Idrus, 2010). This covered the main universities at the time, which included Baghdad (established in 1958), Mustansiriyah (established in 1963), Basra (established in 1967), Mosul (established in 1967), and Technology (established in 1975). However, such improvement has dramatically declined.

The last three decades witnessed a gradual deterioration in Iraqi Higher Education. This is due to the budget deficit as a result of two consecutive wars, sanctions imposed by United Nations, political conflicts, and unsystematic plans. After 2003, as is the case with other sectors in Iraq, Higher Education was affected by the widespread violence in most governorates. According to the UNESCO report, from 2003 to 2012, approximately 500 of Higher Education academic staff were killed (O'Malley, 2014). The report also revealed that 31,600 attacks against universities and schools were recorded by the Iraqi Ministry of Education.

The current Higher Education system comprises about 33 public university and 58 technical institutes all under the management of the MHESR-I. This excludes private universities and educational institutes in the Kurdistan Region Government (KRG). Six universities were established between 2002 and 2007, and 13 were founded in 2014. Out of all institutions, only three were classified in the top 100 Arab ones. These are University of Baghdad ( $\mathrm{N}=18)$, Diyala University $(\mathrm{N}=89)$, and University of Technology Iraq $(\mathrm{N}=100)$ (Webometrics, 2015). The stages of university studies are separated into three levels. 
1. Bachelor's level: granted after four, five, or six years of study based on the discipline. Engineering degrees, for example, are conferred within four years, dentistry and veterinary medicine within five years, and medicine within six years.

2. Master's level: conferred within a minimum of two years. The first year is coursework-led, and if a student has successfully passed the first stage, the second year is based on research only.

3. Doctoral level: the structure of this degree is similar to master's level, except for the period of study, which is at least three years and should result in a piece of novel research.

In order to reform this field, the MHESR-I followed several strategies with limited attention towards incorporating e-learning in Higher Education.

E-Learning in Public Iraqi Universities. Iraqi Higher Education has been deprived for many years from the use of modern learning technologies. As reported by Nour (2002), from 1996 to 2001, there was no information about the use of mobile phones and the internet in Iraq. This is unsurprising because Iraq was the last country in the region that has internet access. It was forbidden for public use until 2000, whereas mobile telephones have only been used since 2003. Since 2010, elearning initiatives have been introduced in many public universities, yet its endorsement is still at a very early stage. In the study conducted by Matar et al. (2010) to identify the figure of e-learning use in the Arab Middle East region, it was pointed out that all countries have achieved various steps of elearning adoption, except for Iraq. Al-Din \& AlRadhi (2008) discuss many challenges that led Iraq to be left behind e-learning enhancement in comparison to neighbouring countries. These include insufficient budget, unstable security, as well as the lack of readiness and encouragement. Currently, six public universities are formally registered as using Moodle including these in the Kurdistan Region Government (KRG) (Moodle, 2016). From the subscribed universities, it is shown that only University of Kufa has implemented it in all colleges, whereas other universities have barely used LMSs.

The first implementation of Iraqi e-learning was in 2010, with University of Kufa being one of the leading institutions in the establishment of e-learning. Moodle was installed and used by few departments as a first experience. An online test with 75 engineers from three departments (civil, mechanic, and electricity) was performed using this platform as a first online-based exam in Iraq. In 2015, all colleges in the university are registered using Moodle.

University of Babylon also leads in this area. LearningCare System (LCS) was developed and implemented in the Department of Computer Science/College of Science in 2010 (Al-Azawei \& Mudheher, 2010). Then, it was replaced with another custom platform at the end of 2011. At the end of 2013, College of Information Technology adopted Moodle as a first step to be used in other colleges. Up to now, only a few of them have started using it, with limited functionalities.

Mustansiriyah University is one of Iraq's most prestigious universities. However, its readiness to adopt e-learning was recently evaluated (Elameer \& Idrus, 2010; Elameer \& Idrus, 2011a; Elameer \& Idrus, 2011b), and the researchers identified many issues that influenced effective e-learning integration, such as lack of internet connection and wireless network being unavailable inside the university. Currently, Moodle is also used by many colleges in this university. Other universities that implemented Moodle are University of Baghdad, University of Information Technology and 
Communications, and University of Kerbala. University of Qadisiyah is applying a custom e-learning system and recently it started implementing Moodle as well.

This brief review does not mean that Iraq cannot develop this sector, even more so since the use of elearning has dramatically increased in the Arab region. In addition, excellent teaching staff, good budget resources, the ability to build a network with international universities, and benefiting from experience of neighbouring countries may aid toward such goal (Al-Din \& AlRadhi, 2008).

In summary, it should be clear that there is a scarcity in the available academic resources or even official reports about the current status of e-learning application in public universities. Moreover, the little research available is quantitative, which could identify the problem from one angle, whereas we need more in-depth evaluation to the current status.

\section{Research Methodology}

Descriptive research design is considered the most appropriate method in this kind of research (Tarus et al., 2015). It has been defined as "research that attempts to describe existing conditions without analyzing relationships among variables" (Fraenkel \& Wallen, 1993). According to Sandelowski (2000; p. 337), descriptive design "tend[s] to draw from the general tenets of naturalistic inquiry.". Findings of this method can be generalized to the entire population if the sample is representative (Tarus et al., 2015). Furthermore, the analysis of a phenomenon is conducted in a completely natural environment without influencing the normal behaviour of subjects (Shuttleworth, 2016). On the other hand, the outcomes cannot be statistically analyzed due to the absence of variables manipulated (Shuttleworth, 2016).

According to Sandelowski (2000), in a case of descriptive research design, a non-probabilistic sampling approach can be used. As such, the present study targeted to choose the main sample from leading public Iraqi universities in e-learning. The collected data was categorized into different groups by applying a thematic approach (Runeson \& Höst, 2009), which has the advantage of classifying qualitative data into several themes in order to infer a general picture. Braun \& Clarke (2006) proposed six phases that can be followed in order to categorize research data into different themes. The researcher's phases are: familiarizing themselves with the data, generating initial codes, searching for themes, reviewing themes, defining and naming themes, and finally, producing the report.

\section{The Study Questions}

Even though there are few studies on the general or specific e-learning application in Iraq (Al-Din \& AlRadhi, 2008; Elameer \& Idrus, 2010; Elameer \& Idrus, 2011a), examinations into challenges for academic members and students in using e-learning technology remain rare. Hence, the aim of this research was to cast some light on barriers imposed on academic members and undergraduate students in public Iraqi universities when it comes to using e-learning technology in teaching and learning. The study was guided by two questions.

1. Which challenges are specified by academic staff and students in the adoption of e-learning technology for teaching and learning in public Iraqi universities?

2. Are the previously identified obstacles to e-learning technology adoption mainly in other developing and Middle East countries similar to these issues in the Iraqi Higher Education? 


\section{Participants}

This study focuses on the use of e-learning in public Iraqi universities. The online instrument was distributed to academic members from different disciplines and universities via social media. Out of them, 27 lecturers were from one university. Their perspectives were also supported by participation of 47 teaching staff from other public universities that are located in different governorates and all of them have made some attempts to implement e-learning. Overall, 108 participants represented the sample size of this research comprising academic staff $(\mathrm{N}=74)$, professors in charge of e-learning $(\mathrm{N}=3)$, and undergraduate students $(\mathrm{N}=31)$. The recruitment of all participants was based on a voluntary approach.

Table 5 shows the general information of teaching staff who participated in the research. Although all of them were from universities that applied either Moodle or custom e-learning systems, results indicated that most have not used e-learning yet. Additionally, it emerges that e-learning is a very new trend in all universities, as the majority of respondents have experienced this technology for less than two years.

Table 5

General Information of Academic Members

\begin{tabular}{lcc}
\hline & Number of participants $=\mathbf{7 4}$ & \\
\hline Factor & $\mathbf{N}$ & $\mathbf{\%}$ \\
\hline Gender & 46 & 62.2 \\
Male & 28 & 37.8 \\
Female & & \\
Years of work experience & 2 & 2.7 \\
$1-3$ & 8 & 10.8 \\
$4-6$ & 13 & 17.6 \\
$7-9$ & 51 & 68.9 \\
$10+$ & & \\
Qualification & 12 & 16.2 \\
Master & 23 & 31.1 \\
PhD Student & 39 & 52.7 \\
PhD & & \\
E-learning system & 13 & 17.6 \\
Custom system & 15 & 20.3 \\
Moodle & 46 & 62.2 \\
None & & \\
Years of using e-learning & 46 & 62.2 \\
O & 12 & 16.2 \\
1 & 11 & 14.9 \\
2 & 4 & 5.4 \\
3 & 1 & 1.4 \\
5
\end{tabular}

\section{Procedure}

In order to collect data, the following two questions were adapted from a prior research that successfully identified hindrances of e-learning application in another developing country (Tarus et al., 2015): 
1. What challenges do public universities in Iraq face that hinder the successful implementation of e-learning?

2. What are your recommendations for addressing these challenges?

Data collection methods included a questionnaire, focus groups, and semi-structured interviews. It was mentioned in the cover page of the online instrument that all data will be dealt with confidentially, for research purposes only, and participants have the right to withdraw from the study when they want.

The questionnaire was distributed online to be filled in by lecturers. It consisted of two parts: the first one identified some general information of the participants, whereas the second part comprised two open-ended questions. It was administered for two weeks.

The focus groups were performed with 57 computer science undergraduate students. All of them have experienced e-learning for approximately one year. First, in a web-design module, students were divided into several groups where each group consisted of three to four students. Ten minutes were given to all groups to think about and discuss possible challenges that they face in using e-learning and what they recommend to tackle them. Then, students were asked to write down their ideas. Finally, each group nominated one student to fill in the online-based survey that was posted on the announcement page of their module website (Moodle). Eight groups (31 students) filled out the online survey, whereas others did not respond.

The third method was semi-structured interviews. This method has the advantage over unstructured interviews in that it allows to cover the main predetermined themes of research. In the latter, on the other hand, participants have the opportunity to freely discuss what they think is important and this, in turn, may divert the direction of the interview in accordance with their perspectives (Saunders, Lewis, \& Thornhill, 2009). Three computer science professors were purposely chosen based on three criteria: they were in charge of the e-learning application, they had individual expertise in the field, and they held high qualifications. All interviews were carried out online and they were recorded and transcribed for documentation purposes.

After collecting data, researchers reviewed all comments in order to identify main themes. Subsequently, all themes were coded to precisely describe the main categories. It is noteworthy that all comments and the conducted interviews were in the Arabic language. After identifying the main themes, the first author has translated the interviews' comments into English in order to be used in the present study. The translation was verified by two Arab PhD students who are studying in the United Kingdom.

\section{Results and Discussion}

This research sought to identify the main challenges in e-learning adoption developing countries face. Generally, responses were classified into either external or internal factors. The former is related to educational institutions or current circumstances in Iraq. The latter, on the other hand, is associated to intrinsic features of users themselves. Table 6 depicts these two categories. The interesting result is that both academic staff and students highlighted similar challenges. This suggests that decisionmakers, leaders, and e-learning administrators should exert great effort to address them. In a case of 
mixed methods, quantitative analysis can be first reported and then it can be supported or rejected by qualitative results (Creswell, Klassen, Clark, \& Smith, 2011).

Table 6

External and Internal Factors as Identified by Participants

\begin{tabular}{lcccc}
\hline & N of lecturers= 74 & \multicolumn{2}{c}{$\begin{array}{c}\text { N of students }=\mathbf{3 1}, \\
\text { Groups }=\mathbf{8}\end{array}$} \\
\hline External Challenges & $\mathbf{N}$ & $\mathbf{\%}$ & Group & $\mathbf{\%}$ \\
Low internet bandwidth & 17 & 22.97 & 5 & 62.5 \\
Insufficient financial support & 13 & 18.91 & 2 & 25 \\
Inadequate training programs & 40 & 54.05 & 5 & 62.5 \\
Lack of technical support & 15 & 20.27 & 2 & 25 \\
Lack of ICT infrastructure & 33 & 43.24 & 4 & 50 \\
Ambiguous plan and policies & 16 & 21.62 & 1 & 12.5 \\
Frequent electricity shortage & 5 & 6.75 & 1 & 12.5 \\
Internal Challenges & $\mathbf{N}$ & $\mathbf{\%}$ & Group & $\mathbf{\%}$ \\
ICTS and E-learning literacy & 23 & 31.08 & 4 & 50 \\
Lack of awareness, interest, and motivation & 35 & 47.29 & 6 & 75 \\
\hline
\end{tabular}

\section{External Challenges}

External challenges include technical implementation of e-learning. Looking at the results in Table 6, many lecturers (22.97\%) and most students (62.5\%) agreed that low internet bandwidth is one of the issues hindering successful application of e-learning in Iraq. Users need a long time to upload or download, for example, pictorial learning materials such as videos, graphs, and animations. The present study reveals that low internet connectivity, whether at a university or home, is a preventing factor to e-learning use as highlighted by prior literature (Mirza \& Al-Abdulkareem, 2011; Tarus et al., 2015). It is noteworthy that students have identified this issue more than lecturers because they may not be able to afford, for example, the "golden" internet service that provides faster internet connectivity, whereas instructors can. One of the lecturers interviewed explained:

low internet bandwidth is the underlying factor when it comes to infrastructural issues... if elearning is applied in all colleges or we want to connect this system with other universities, the problem of low internet signal will face us and this, in turn, will influence this experience.

Another hindrance towards e-learning application in accordance with lecturers (18.91\%) and students (25\%) is the shortage of funding. Generally, the budget of Higher Education in Iraq is adequate in comparison to other sectors, but there is a need to allocate a specific financial fund to e-learning. Currently, most of the allocated budget is spent for the establishment of new buildings in order to absorb the increased number of students. However, more attention should be given for the requirements of e-learning integration. Other literature also found that lack of financial support is one of the main obstacles that affects e-learning implementation (Khan et al., 2012; Sife et al., 2007; Tarus et al., 2015). Furthermore, the possible e-learning systems that can be used are commercial systems such as Blackboard, custom applications that are developed to specific requirements of organizations, or open source LMSs (OS-LMSs). The main issues with the former are the high maintenance cost and inflexibility to be adapted to an institute's specific needs (Sife et al., 2007). Regarding custom applications, the most prominent issue is the lack of reliability. Thus, in order to avoid unaffordable expenses of commercial systems and unreliability of custom applications, OS-LMSs such as Moodle 
can be adopted. According to previous studies, this software has gained significant attention worldwide (Al-Ajlan, 2012; Cavus \& Zabadi, 2014; Graf, 2007). The following response from interviews confirmed this

lack of funding is another challenge that Iraqi universities face in implementing e-learning, more specifically, nowadays where there is a general deficit. . . there is [currently] no allocated budget for e-learning, but universities have a plan to allocate part of their [general] budget for e-learning.

In addition, Table 6 shows that most lecturers (54.05\%) and students (62.5\%) pointed out that intensive training programs are required in order to enhance user skills towards computer and elearning technologies. Undoubtedly, lack of individual skills can negatively affect their intention to use e-learning. Prior studies quantitatively proved the effect of e-learning self-efficacy on learner perceptions such as satisfaction, perceived usefulness, perceived ease of use, and intention to accept technology (Al-Azawei \& Lundqvist, 2015; Hong, Thong, James, Wong, \& Tam, 2001; Ong \& Lai, 2006; Sun et al., 2008). The present qualitative analysis supports such outcomes. It suggests that there is an obvious lack of support from educational institutions to improve user confidence in adopting such technologies. As a consequence, users face difficulty with e-learning and this, in turn, may lead them to seek different reasons to avoid it. Earlier literature also highlighted this issue (Ali \& Magalhaes, 2008; Al-Shboul, 2013). In our interviews, this was clear from all respondents that:

we should attempt to spread the e-learning culture by holding workshops, conferences, and inviting experts in this field, whether from Iraq or other international institutions, so as to benefit from their experience. . . and there is a need to conduct training programs [for Iraqi academic staff] in international universities that have extensive experience in this sector.

Further:

we need to conduct training programs to [sic] all instructors in order to show them the advantages of e-learning systems and how to use these technologies. . . and attempt to involve students in such experience... where they need illustrative lectures.

Successful implementation of any technology cannot be achieved without professional technical staff to set up and maintain it. As demonstrated in Table 6, instructors (20.27\%) and students (25\%) found that there is a lack of technical support to address issues that users may face. This result is consistent with findings of studies which pointed out that insufficient technical support is a key challenge to fostering e-learning (Al-Shboul, 2013; Sife et al., 2007; Ssekakubo et al., 2011). This means that preparation of professional staff should be a first step before launching a system. As such, any failing in the system can be directly tackled to prevent user disruption. One respondent who was interviewed commented that

... [there is a] limit number of experts, more specifically, in the networks' field to manage the system and solve any problems that users may face.

Table 6 also shows that many lecturers (43.24\%) and students (50\%) believe that an inadequate ICT infrastructure is one of the major challenges that hinders e-learning integration in public universities. As stated by participants, this entails non-availability of special laboratories, lack of free internet inside universities, and not enough number of computers. This finding confirms the investigation of 
Elameer \& Idrus (2010) where the authors stated that there were no wireless networks inside a university campus. Although public universities witnessed a good development in ICT infrastructure after 2003, it is evident from this analysis that the project is still under development. An integrated infrastructure as a preliminary step to adopting e-learning should include free Wi-Fi and network connections in campuses. Furthermore, laboratories should be supplied with enough computers. In keeping with literature, this was also identified as a core challenge to fulfill objectives of e-learning implementation (Abdelraheem, 2006; Khan et al., 2012; Matar et al., 2010; Tarus et al., 2015). This problem was also mentioned by all respondents during interviews:

poor infrastructure: this includes enough servers, laboratories, computers, and internet and/ or intranet networks inside the university. If we want to apply e-learning, we should build the infrastructure and then move to the next step... insufficient infrastructure means e-learning implementation will fail before starting either directly or indirectly.

And again:

The important thing that should be firstly implemented is ICT infrastructure. Some colleges do not have infrastructure such as information networks, servers, computers, software, and laboratories that are connected with a network, and this hinders e-learning application.

Looking further to Table 6, some lecturers (21.62\%) and students (12.5\%) referred to ambiguous policies preventing the implementation of e-learning. Even though the MHESR-I aimed to integrate ICTs and e-learning in Higher Education, this requires a systematic approach, from the preparation of principal requirements, to installation, execution, testing, and monitoring. The lack of proper strategies to foster e-learning was also accounted as a hindrance in relevant studies (Khan et al., 2012; Tarus et al., 2015). An interviewee also commented that:

there are improvisational steps to implement e-learning. They started from computer science colleges and other colleges that support this notion. Currently, there is no clear plan, but there will be in the near future, as the University is soon to start using central servers. . . . It has initially been endorsed by one college, to subsequently spread to others, too.

Furthermore, results in Table 6 also demonstrated that few lecturers (6.75\%) and students (12.5\%) considered frequent electricity shortage as a factor that negatively influenced successful e-learning implementation in Iraq. This issue emerged in 1991 after the first Gulf War, and up to now, there has been little improvement. On the other hand, people use many alternative methods to get their minimum requirements of electricity. This may explain why only a few participants have mentioned this as a challenge that affects the application of e-learning.

Some individual respondents identified other barriers: (1) Lack of electronic Arabic resources for humanitarian disciplines; thus the preparation of e-lectures requires greater effort. This was also confirmed by literature (Matar et al., 2010); (2) There is no rigorous law to protect copyright in Iraq, so there is fear of plagiarism if lectures are uploaded electronically; (3) The current unstable circumstances in Iraq, such as corruption and war. This is one of the important identified obstacles that could negatively affect the adoption of e-learning. Currently, the global war on terrorism affects all aspects of public life in Iraq, education included. 


\section{Internal Challenges}

Internal challenges are more relevant to user willingness to move from traditional to more advanced teaching and learning approaches. Additionally, some users believe that e-learning means delivering learning content electronically by, for example, computer, iPhone, and mobile devices, whether offline or online. E-learning, however, entails a much wider concept than this superficial perspective. It includes exploiting the advantages of e-learning malleability to integrate pedagogical and learning theories. Derouin et al. (2005) indicate that e-learning is an adequate technology to merge effective educational theories as opposed to solely using it as an information delivery agent. An example of such theories is the multimedia principles theory (Mayer, 2009). Its notion is based on blending graphics and texts in e-learning content rather than mere text only.

The results in Table 6 exhibit that many lecturers (31.08\%) and half of students (50\%) consider ICT and e-learning illiteracy to be hindering the effective integration of e-learning. Unsurprisingly, modern instructional technologies have recently been introduced to the Iraqi Higher Education context. Therefore, older teaching members and those from humanitarian fields are unfamiliar with such technologies. Ssekakubo et al. (2011) and Tarus et al. (2015) also found that this is an issue in developing nations. Successful implementation of e-learning cannot be achieved without developing individual skills. Two respondents who were interviewed agreed that the lack of ICT skills is another obstacle, describing that

it is difficult to persuade academic staff dedicated to traditional F2F methods to endorse elearning. . . so they find difficulty in preparing e-lectures. . . in summary, there is a problem in using modern learning technologies.

Table 6 also demonstrates that both staff (47.29\%) and students (75\%) pinpoint unwillingness, disinterest, and demotivation as other major challenges that hinder e-learning uptake. Some users resist any new experience. Respondents mentioned several aspects that could lead to such a negative attitude. For instance, the preparation of e-learning content requires more time than the traditional approach; e-learning will reduce teacher roles in educational practice; and the advantage of e-learning is limited to uploading electronic lectures only. Based on such perspectives, they have not found a difference between e-learning and other communication technologies such as email or even distributing written lectures in classrooms. Khan et al. (2012) stated that lecturers need to take a positive attitude toward e-learning. Accordingly, huge effort should be directed towards extending their academic understanding about the potential pedagogical impacts of e-learning on different learning aspects such as learner performance, satisfaction, and engagement. Academic staff should have an obligation to implement e-learning in order to fulfill the goals of all students more easily and enjoyably. Another possible reason of low attitude and interest in e-learning adoption is English proficiency. Whilst users need acceptable English skills in order to use the available learning technologies and e-resources, the overall English proficiency of Iraqi academic staff and students is either mild or moderate (Borg, 2015). Interviewees also mentioned this challenge:

as well as lecturers' belief in using electronic technologies such as computers and web pages. . . teacher motivation to use e-learning is low. . . most lecturers lack knowledge in such types of systems, and need training courses to understand their benefits. . . students are reluctant to try what they have not experienced, but of course if it is implemented they will be eager to use it. 
Further, that

there is considerable unawareness of most lecturers and students about the advantages of elearning and what such systems may offer. ... It is the absence of motivation that prevents teachers to interact with e-learning.

\section{Recommendations}

From this analysis, it can be clearly indicated that a successful implementation of e-learning is not something that can be achieved by, for example, installing an e-learning system and providing access for all users. However, a set of initial steps must precede e-learning application. This study provides some recommendations that can be followed in order to fulfill the objectives of e-learning implementation in Iraqi public universities. These recommendations were inspired from the respondents' comments.

- A systematic strategy should be followed to implement e-learning. Since it is a new experience for Iraqi universities, we highly recommend collaboration with other universities that have achieved advanced steps in e-learning application, whether from neighbouring or developed countries.

- A budget for establishing an integrated ICT infrastructure and e-learning should be prioritized, as well as other necessary requirements. Adopting OS-LMSs can reduce expenses of software licensing and maintenance.

- Preparing professional technical staff is a vital step in order to maintain e-learning and support users. If learners or instructors face any difficulty, quick support should be provided to avoid user disruption.

- Intensive training programs are needed and they should be driven in two directions. The first one is to familiarize users with e-learning functionalities and improve their self-confidence in using it. Furthermore, experts in e-content development and e-learning pedagogical theories should present the potential implications of e-learning on educational practice.

- Engaging users is a cornerstone of embracing e-learning effectively. As an example of academic staff engagement, reward can be allocated for lecturers who widely and effectively exploit e-learning features in their teaching approaches. According to Govindasamy, (2002), educational institutions can introduce a competition for best e-content development. Students, on the other hand, can be rewarded, for instance, with extra marks, if they use elearning effectively.

- In Iraq, academic staff cannot teach at a tertiary level until attending and successfully passing a teaching methods course. Hence, we recommend integrating e-learning theories in the syllabus of such courses.

- We also suggest including e-learning use as another criterion in the yearly assessment method that is used to evaluate teaching staff performance. This can encourage e-learning application.

\section{Conclusion}


The present research aimed to cast some light on major challenges that hinder effective application of e-learning in developing nations. A case was chosen from Iraq because e-learning has been recently implemented in some public universities. Findings exhibited that the use of e-learning in Iraq is still at a very early stage. In addition, it was illustrated that most public universities have started limited attempts to apply either custom or open source e-learning applications, but the majority of academic staff still do not have enough knowledge and skills to use it properly. This investigation confirmed the findings of existing studies about obstacles to e-learning integration in developing countries, and filled the gap regarding the Iraqi context. Causes that led Iraq to be later to implement e-learning may encompass the previous isolation of staff members from the scientific world, the delay of introducing e-learning technologies to Higher Education, and the continuous national instability and insecurity.

Pertaining to the present investigation, seven external and two internal challenges were demonstrated as a result of the quantitative and qualitative analysis. The main barriers comprised, but were not limited to, low internet bandwidth, insufficient financial support, inadequate training programs, lack of technical support, lack of ICT infrastructure, ambiguous policies and objectives, frequent electricity shortage, ICTs and e-learning illiteracy, and lack of awareness, interest, and motivation toward elearning technology. The key issues as identified by the majority of participants were lack of training programs and inadequate ICT infrastructure. Based on the discussed barriers, many recommendations were provided. We hope that following them can lead to effective e-learning integration in public Iraqi universities. Regardless of the identified issues, there is a promising consideration from the MHESR-I and universities to develop e-learning implementation. It is hoped that in the near future we will witness evolution in the e-learning sector as in other neighbouring countries. This goal cannot be achieved without efforts initiated by MHESR-I, leaderships, teaching staff, supportive staff, and students.

\section{Acknowledgment}

The authors are grateful to the Iraqi Ministry of Higher Education and Scientific Research for supporting this study. They would also like to thank all participants in this research for their valuable comments.

\section{References}

Abdelraheem, A. Y. (2006). The implementation of e-learning in the Arab Universities: Challenges and opportunities. In DLI 2006, Tokyo, Japan, 145-154.

Al Musawi, A. S., \& Abdelraheem, A. Y. (2004). E-learning at Sultan Qaboos university: Status and future. British Journal of Educational Technology, 35(3), 363-367. doi:10.1111/j.00o71013.2004.00394.x

Al-Ajlan, A. S. (2012). A comparative study between e-learning features. In Methodologies, tools and new developments for e-learning (pp. 191-214). New York: InTech Open Access. Retrieved from http://cdn.intechweb.org/pdfs/27926.pdf

Al-Azawei, A., \& Lundqvist, K. (2015). Learner differences in perceived satisfaction of an online learning: An extension to the Technology Acceptance Model in an Arabic sample. Electronic Journal of E-Learning, 13(5), 408-426. 
Al-Azawei, A., \& Mudheher, W. W. (2010). Designing an online learning care system for University of Babylon ( LCS ). In The Fifth Scientific Conference. Iraq: University of Babylon (pp. 398409).

Al-Din, A., \& AlRadhi, K. (2008). Distance learning / e-learning for Iraq: Concept and road map. American Society for Information Science and Technology, 34(3), 34-37.

Ali, G. E., \& Magalhaes, R. (2008). Barriers to implementing e-learning: a Kuwaiti case study. International Journal of Training and Development, 12(1), 36-54.

Alias, N., \& Zainuddin, A. (2005). Innovation for better teaching and learning: Adopting the learning management system. Malaysian Online Journal of Instructional Technology, 2(2), 27-40.

Al-Senaidi, S., Lin, L., \& Poirot, J. (2009). Barriers to adopting technology for teaching and learning in Oman. Computers and Education, 53(3), 575-590. doi:10.1016/j.compedu.2009.03.015

Al-Shboul, M. (2013). The level of e-learning integration at the University of Jordan: Challenges and opportunities. International Education Studies, 6(4), 93-113. doi:10.5539/ies.v6n4p93

Al-Shboul, M., \& Alsmadi, I. (2010). Challenges of utilizing e-learning systems in public universities in Jordan. International Journal of Emerging Technologies in Learning, 5(2), 4-10. doi:10.3991/ijet.v5i2.1147

Andersson, A. (2008). Seven major challenges for e-learning in developing countries: Case study eBIT, Sri Lanka. International Journal of Education and Development Using Information and Communication Technology, 4(3), 45-62.

Borg, S. (2015). English medium instruction in Iraqi Kurdistan. Retrieved from http://englishagenda.britishcouncil.org/sites/default/files/attachments/teaching_english_p ublication_en_web_version_v1.pdf

Braun, V., \& Clarke, V. (2006). Using thematic analysis in psychology. Qualitative Research in Psychology, 3(2), 77-101. doi:10.1191/1478088706qpo63oa

Cavus, N., \& Zabadi, T. (2014). A comparison of open source learning management systems. Procedia - Social and Behavioral Sciences, 143, 521-526. doi:10.1016/j.sbspro.2014.07.430

Creswell, J. W., Klassen, L. a. C., Clark, V. L. P., \& Smith, L. K. C. (2011). Best practices for mixed methods research in the health sciences. Office of Behavioral and Social Sciences Research National Institutes of Health, National Institutes of Health, Bethesda, MD: 2012 Retrieved from https://obssr.od.nih.gov/training/mixed-methods-research/

Derouin, R. E., Fritzsche, B. A., \& Salas, E. (2005). E-learning in organizations. Journal of Management, 31(6), 920-940. doi:10.1177/0149206305279815

Elameer, A. S., \& Idrus, R. M. (2011a). National e-learning strategy to enhance and enrich the Iraqi Universities. US-China Education Review A 4, 481-496. 
Elameer, A. S., \& Idrus, R. M. (2011b). Orbital e-education framework for the University of Mustansiriyah (UoMust). TOJET: The Turkish Online Journal of Educational Technology, $10(4), 165^{-173 .}$

Elameer, A. S., \& Idrus, R. M. (2010). The readiness for an e-learning system in the University of Mustansiriyah (UoMust) Baghdad-Iraq. Malaysian Journal of Educational Technology, $10(2), 31-41$.

Elzawi, A., \& Wade, S. (2012). Barriers to ICT adoption in quality of engineering research in Libya: how to bridge the digital divide. In: Proceedings of The Queen's Diamond Jubilee Computing and Engineering Annual Researchers' Conference 2012: CEARC'12 (pp. 98-103). University of Huddersfield, Huddersfield, UK.

Fraenkel, J.R. \& Wallen, N.E., 1993. How to design and evaluate research in education. New York: McGraw-Hill.

Govindasamy, T. (2002). Successful implementation of e-learning pedagogical considerations. Internet and Higher Education, 4(3), 287-299.

Graf, S. (2007). Adaptivity in learning management systems focussing on learning styles (Doctoral dissertation). Vienna University of Technology, Vienna.

Gulati, S. (2008). Technology-enhanced learning in developing nations: A review. International Review of Research in Open and Distance Learning, 9(1), 1-16.

Hong, W., Thong, James, Y. L., Wong, W. M., \& Tam, K. Y. (2001). Determinants of user acceptance of digital libraries: An empirical examination of individual differences and systems characteristics. Journal of Management Information Systems, 18(3), 97-124. doi:10.1080/07421222.2002.11045692

Internet World Stats. (2015). Internet usage in the Middle East. Retrieved from http://www.internetworldstats.com/stats5.htm

Kaghed, N., \& Dezaye, A. (2009). Quality assurance strategies of higher education in Iraq and Kurdistan: A case study. Quality in Higher Education, 15(1), 71-77. doi:10.1080/13538320902731286

Khan, S. H., Hasan, M., \& Clement, C. K. (2012). Barriers to the introduction of ICT into education in developing countries: The example of Bangladesh. International Journal of Instruction, 5(2), 61-80.

Matar, N., Hunaiti, Z., Halling, S., \& Matar, Š. (2010). E-learning acceptance and challenges in the Arab Region. In S. Abdallah \& F. Albadri (Eds.), ICT acceptance, investment and organization: Cultural practices and values in the arab world (pp. 184-200). Hershey, PA: Information Science Reference. doi:10.4018/978-1-60960-048-8.cho13

Mayer, R. E. (2009). Multi-media learning (2nd ed.). Cambridge: Cambridge University Press. 
Mirza, A. a., \& Al-Abdulkareem, M. (2011). Models of e-learning adopted in the Middle East. Applied Computing and Informatics, 9(2), 83-93. doi:10.1016/j.aci.2011.05.001

Moodle. (2016). Moodle. Retrieved January 4, 2016, from https://moodle.net/sites/index.php?country=IQ

Nour, S. S. O. M. (2002). ICT opportunities and challenges for development in the Arab World (Discussion paper No. 2002/83). United Nations University World Institute for Development Economics (UNU-WIDER).

O’Malley, B. (2014). Education Under Attack 2014. Retrieved from http://protectingeducation.org/sites/default/files/documents/eua_2014_full_o.pdf

Ong, C. S., \& Lai, J. Y. (2006). Gender differences in perceptions and relationships among dominants of e-learning acceptance. Computers in Human Behavior, 22(5), 816-829. doi:10.1016/j.chb.2004.03.006

Procter, C. (2003). Blended learning in practice. In Education in a Changing Environment 17th-18th. UK: University of Salford. Retrieved from http://usir.salford.ac.uk/27428/2/BlendedLearningInPractice.pdf

Pulkkinen, J. (2007). Cultural globalization and integration of ICT in education. Oulu, Finland: University of Oulu, 13-23.

Runeson, P., \& Höst, M. (2009). Guidelines for conducting and reporting case study research in software engineering. Empirical Software Engineering, 14(2), 131-164. doi:10.1007/s106640o8-9102-8

Saheb, T. (2005). ICT, Education and Digital Divide in Developing Countries. Global Media Journal, $4(7), 1-8$.

Sandelowski, M. (2000). Focus on Research Methods: Whatever happened to qualitative description? Research in Nursing \& Health, 23(4), 334-340. doi:10.1002/1098240x(200008)23:4<334::aid-nur9>3.0.co;2-g

Saunders, M., Lewis, P., \& Thornhill, A. (2009). Research methods for business students (Fifth.). Pearson Education.

Shuttleworth, M. (2016). Descriptive research design. Retrieved January 6, 2016, from https://explorable.com/descriptive-research-design

Sife, A. S., Lwoga, E. T., \& Sanga, C. (2007). New technologies for teaching and learning: Challenges for higher learning institutions in developing countries. International Journal of Education and Development Using Information and Communication Technology, 3(2), 57-67.

Ssekakubo, G., Suleman, H., \& Marsden, G. (2011). Issues of adoption: Have e-learning management systems fulfilled their potential in developing countries? Proceedings of the South African Institute of Computer Scientists and Information Technologists Conference on Knowledge, Innovation and Leadership in a Diverse, Multidisciplinary Environment - SAICSIT'11 (pp. 
231-238). New York, NY: Association for Computing Machinery.

doi:10.1145/2072221.2072248

Sun, P.-C., Tsai, R. J., Finger, G., Chen, Y.-Y., \& Yeh, D. (2008). What drives a successful e-Learning? An empirical investigation of the critical factors influencing learner satisfaction. Computers \& Education, 5O(4), 1183-1202. doi:10.1016/j.compedu.2006.11.007

Taha, A. (2007). Networked e-information services to support the e-learning process at UAE University. The Electronic Library, 25(3), 349-362. doi:10.1108/02640470710754850

Tarus, J. K., Gichoya, D., \& Muumbo, A. (2015). Challenges of implementing e-learning in Kenya: A case of Kenyan public universities. International Review of Research in Open and Distributed Learning, 16(1), 120-141.

Watt, C. (2012). Education, ICT and OER in the United Arab Emirates Education in UAE Policy. Retrieved from http://poerup.referata.com/w/images/OER in UAE edited.pdf

Webometrics. (2015). Ranking web of universities. Retrieved from http://www.webometrics.info/en/arab world

Yamani, H. A. (2014). E-learning in Saudi Arabia. Journal of Information Technology and Application in Education, 3(4), 169. doi:10.14355/jitae.2014.0304.10

Zamani, B. E., \& Esfijani, A. (2016). Major barriers for participating in online teaching in developing countries from Iranian faculty members' perspectives. Australasian Journal of Educational Technology, 32(3), 38-49.

Zhang, D., Zhao, J. L., Zhou, L., \& Nunamaker, J. F. (2004). Can e-learning replace classroom learning? Communications of the ACM, 47(5), 75-79. doi:10.1145/986213.986216

\section{Athabasca \\ University}

(C) (1) 